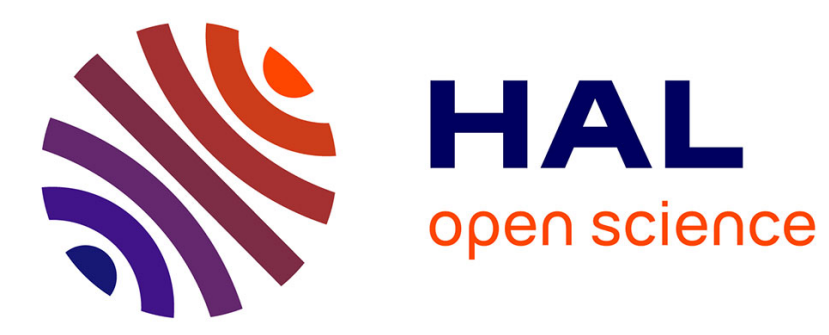

\title{
Living in the Garden of Eden: Mineral Resources and Preferences for Redistribution
}

\author{
Mathieu Couttenier, Marc Sangnier
}

\section{To cite this version:}

Mathieu Couttenier, Marc Sangnier. Living in the Garden of Eden: Mineral Resources and Preferences for Redistribution. 2015. halshs-01111544

\section{HAL Id: halshs-01111544 https://shs.hal.science/halshs-01111544}

Preprint submitted on 30 Jan 2015

HAL is a multi-disciplinary open access archive for the deposit and dissemination of scientific research documents, whether they are published or not. The documents may come from teaching and research institutions in France or abroad, or from public or private research centers.
L'archive ouverte pluridisciplinaire HAL, est destinée au dépôt et à la diffusion de documents scientifiques de niveau recherche, publiés ou non, émanant des établissements d'enseignement et de recherche français ou étrangers, des laboratoires publics ou privés. 


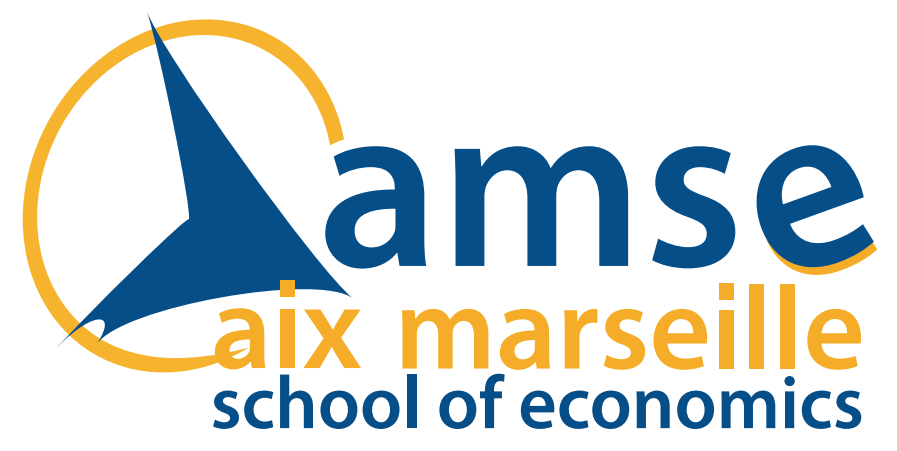

\section{Working Papers / Documents de travail}

\section{Living in the Garden of Eden: Mineral Resources and Preferences for Redistribution}

Mathieu Couttenier

Marc Sangnier 


\title{
Living in the Garden of Eden: Mineral Resources and Preferences for Redistribution*
}

\author{
Mathieu CouttenieR ${ }^{a}$ Marc SANGnieR $^{b}$
}

January 2015

\begin{abstract}
This paper provides empirical evidence that mineral resources abundance is associated to preferences for redistribution in the United States. We show that individuals living in states with large mineral resources endowment are more opposed to redistribution than others. We take advantage of both the spatial and the temporal distributions of mineral resources discoveries since 1800 to uncover two mechanisms through which mineral resources can foster ones' opposition to redistribution: either by transmission of values formed in the past, or by the exposure to mineral discoveries during individuals' life-time. We show that both mechanisms matter to explain respondents' preferences.
\end{abstract}

Keywords: Redistribution, Mineral Resources, Persistence.

JEL CODES: Z10, Q32, O10.

*We thank Yann Algan, Rémi Bazillier, Pierre Cahuc, Andrew Clark, Paola Conconi, Lionel Fontagné, Luigi Guiso, Rachel Kranton, Thierry Mayer, Rodrigo Paillacar, Paul Seabright, Claudia Senik, Mathias Thoenig, Julien Vauday, Thierry Verdier, Romain Wacziarg, and Yanos Zylberberg for helpful comments. We thank the audience at NBER Political Economy Program Meeting 2012 and at EEA Congress 2011, as well as seminar participants at Sciences Po Paris, at the Paris School of Economics, and at the AixMarseille School of Economics for useful remarks. Mathieu Couttenier acknowledges financial support from the ERC Starting Grant GRIEVANCES-313327. This paper was previously circulated under the title "Living in the Garden of Eden: Mineral Resources Foster Individualism".

${ }^{a}$ HEC-University of Lausanne; mathieu.couttenier@unil.ch (corresponding author); +41 (0)21 69234 84; Université de Lausanne, Quartier UNIL-Dorigny, Bâtiment Extranef, 1015 Lausanne, Switzerland

${ }^{b}$ Aix-Marseille Univ. (Aix-Marseille School of Economics), CNRS \& EHESS (previously: Paris School of Economics and Sciences Po Paris, Department of Economics); Email: marc.sangnier@univ-amu.fr 


\section{Introduction}

Beliefs and values have gained much attention as determinants of economic outcomes (see Fernández (2011) for a review). However, the question of values' origin is still under scrutiny by the empirical literature. This paper focuses on the United States and provides evidence that mineral resources abundance is associated with lower support for redistribution.

We take advantage of geo-referenced information on mineral resources' discoveries in United States over the 1800-2000 period. We observe the effects of both the spatial and temporal differences in the distribution of mineral discoveries across states and time on individuals' preferences for redistribution. Our measure of such preferences is the first principal component of answers on two questions of the General Social Survey that capture support for individual responsibility and sympathy for income inequality.

We show that individuals living in states with large mineral resources endowment are more opposed to redistribution than others. We undertake various tests and strategies to demonstrate the robustness of this result. We then examine how an individual acquires such values. We highlight two mechanisms through which mineral resources can foster ones' opposition to redistribution: either by transmission of values formed in the past, or by the exposure to mineral discoveries during individuals' life-time. We show that both mechanisms matter to explain respondents' preferences.

A history of American mining, written by Rickard in 1932, illustrates the extent to which mining is associated with the concept of individuals' self-reponsibility in the American tradition. This book has been written "to give [...] something of that background the older men built up as they went along". The introduction argues that "in developing the mineral wealth of a continent [...] things do not "just happen"; they are brought about by men who have the wit to see and the courage to do. Our predecessors were men with these qualities. They [...] have left us a great heritage". ${ }^{1}$ This heritage is made of values such as individual responsibility that are deeply associated with mining activity. This is mostly the case because of the technical methods used in the early times of mining in the Unites States. As documented by Freudenburg and Frickel (1994), "mining operations and technologies were small-scale, and [...] capital requirements were minimal". These operations could often be implemented by a single man. ${ }^{2}$ Mining was more labor- rather than capital-intensive. ${ }^{3}$

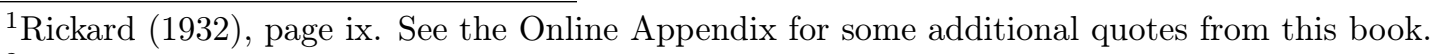

${ }^{2}$ According to Braunstein (1985), mining has quickly turned into an activity run by large corporations. A recent paper by Glaeser et al. (2014) builds on this observation and document a negative relationship between large-scale historical mining and today's entrepreneurship across American cities. Yet, the myth of the single gold miner still persisted despite subsequent technological transformations of the mining industry.

${ }^{3}$ This feature also translates into unionization patterns. According to numbers from Friedman (1999), the mining industry was the second most unionized industry in the United States in 1880 (the unionization rate in mining industry was $11.35 \%$, just below the unionization rate in printing industry that was equal
} 
The positive association between mineral resources and opposition to collective redistribution that we uncover in this paper could be explained by some income effect. Natural resources create wealth opportunities that can benefit to local residents if they provide sufficient efforts. This windfall induced by natural resources can be related to the well-known effect of income on the demand for redistribution à la Romer (1975), Meltzer and Richard (1981), and Piketty (1995): increasing income is associated with less willingness to redistribute. This association is stronger the larger the efforts made to obtain this increasing income. This mechanism has been documented by Alesina and La Ferrara (2005), Alesina and Angeletos (2005), and Alesina and Giuliano (2011) among others. These scholars describe the genesis of values that may be transmitted between individuals and generations. However, a key feature of this paper is that our empirical results persist when various measure of individual and collective income are taken into account. This suggests that mineral resources are also associated with particular characteristics that go beyond their transaction value. Among these characteristics, it is worth noting the role of effort in the exploitation of mineral resources as suggested by the narrative of American mining history. The role of effort is also a dimension that distinguishes our finding on mineral resources from those of other scholars about the relationship between taste for redistribution or collectivism and oil revenues (Di Tella et al. 2010) or agricultural shocks (Davis 2014).

As Bisin and Verdier (2001), the literature points out two main mechanisms through which values are formed at the individual level. First, values can be inherited through family transmission of traits. Second, values can be shaped through the socialization process: individuals interact with others and mix their traits. The first process refers to transmission, whereas the second concerns the context in which individuals evolve. We take inspiration from this approach to study how mineral resources discoveries can affect values held by respondents. We also consider two mechanisms. The first mechanism is linked to the question of transmission and persistence of beliefs. It occurs within society, across and within generations. In other words, values are inherited from the family or from others and transmitted over time in a given group. We refer to this mechanism as the transmission mechanism. ${ }^{4}$ The second mechanism is linked to the immediate effect of mineral resources discoveries have on preferences for redistribution. Values depend on events that happened during the life of an individual. Hence, "shocks" on mineral resources abundance are likely to directly shape the values held by individuals if they

to $11.70 \%$ ). This fact should however not be over-interpreted since unionization may reflect either general political orientations or a local protection behavior. See Riley (1997), Schnabel (2003), and Schnabel and Wagner (2007) for developments of this issue. Todays unionization rate in mining industry is roughly equal to the average unionization rate in the American economy according to the Bureau of Labor Statistics.

${ }^{4}$ This mechanism is close to the "direct vertical socialization" proposed by Bisin and Verdier (2008) but where the cultural transmission is done within the family. Note that the transmission of cultural traits may be implicit or explicit. The latter case can be illustrated by the already mentioned book $A$ history of American mining (Rickard 1932). 
have been exposed to these shocks. In what follows, we refer to this mechanism as the exposure mechanism.

A contribution of this paper is to disentangle the existence and the relative importance of these two mechanisms for the main relationship described above. We do so by isolating individuals that are likely to have been exposed to mineral resources discoveries in the state where they live over their life-time. These respondents appear to be more opposed to redistribution than those who did not have such experiences but live in states with lots of mineral resources. The latter are themselves more opposed to redistribution than those living in states with low mineral resources endowment. This result allows us to show that both mechanisms matter. A back-of-the-envelope calculation leads to the following conclusion: the exposure mechanism accounts for about $35 \%$ of the overall difference in preferences for redistribution between mineral and non-mineral states (the remaining $65 \%$ are accounted for by the transmission mechanism).

Our results mean that mineral resources have an effect on attitudes. Diamond (2006) highlights the interplay between the abundance of natural resources and individual orientations thanks to the case study of Montana. He claims that natural resources abundance is part of the state's identity and partly shapes individual beliefs about economic organization. $^{5}$ All in all, this paper offers evidence that mineral resources influence the values held by people living in areas that are affluent in such resources. It shows one channel through which economic and natural environments affect individuals' values and is therefore related to the literature interested in the formation and the persistence of values and beliefs. Although still in infancy, this literature's empirical side is quickly expanding. ${ }^{6}$

The contributions by Di Tella et al. (2010) and Davis (2014) are the closest to our focus on preferences for redistribution. Davis (2014) argues that individual exposure to rainfall variations in preindustrial society had an influence on beliefs and attitudes that are persistent today. More especially, he claims that the exogenous exposure to agricultural risk, approximated by the prevalence of monthly rainfall variations, lead people to develop less individualistic values. Di Tella et al. (2010) were the first to provide robust empirical evidence about the relationship between resources abundance and the support for collective redistribution by studying how exogenous changes in oil revenues affect individuals willingness to redistribute. They conclude "that societies that depend heavily on oil [...] experience heavier demand for government intervention".

${ }^{5}$ See the Online Appendix for a short presentation of the text by Diamond (2006) on Montana.

${ }^{6}$ Di Tella et al. (2007) study how the allocation of property rights shaped squatters' beliefs in Buenos Aires. Guiso et al. (2008) link today's social capital in Italy to medieval institutional arrangements. Durante (2009) argues that historical climatic variability shapes attitudes towards cooperation across European regions. Luttmer and Singhal (2011) provide evidence on the importance of culture and context in preferences for redistribution. Nunn and Wantchekon (2011) show that past slave trade shapes today's mistrust in Africa. Grosfeld et al. (2013) show how persistent anti-Semitism still translates into anti-market culture in Europe. Giuliano and Spilimbergo (2014) provide evidence that macroeconomic fluctuations during early adulthood partly determine the support for redistribution and confidence in institutions. 
The remainder of this paper is organized as follows. Section 2 presents the data and the methodology. Section 3 presents empirical results and discusses them. Finally, section 4 briefly concludes.

\section{Data and methodology}

This section presents the data and the methodology used in this paper.

\subsection{Data on preferences for redistribution}

We use a first principal component analysis to construct our measure of opposition to redistribution. The two questions used in the factor analysis are from the General Social Survey (GSS). ${ }^{7}$

The first question has also been used by Di Tella et al. (2010). It reads as follows: "Some people think that the government in Washington should do everything possible to improve the standard of living of all poor Americans. Other people think it is not the government's responsibility, and that each person should take care of himself. Where would you place yourself on this scale?". Possible answers are "1 (I strongly agree that the government should increase living standards), 2, 3 (I agree with both answers), 4, 5 (I strongly agree that people should take care of themselves)". Answers to this question are supposed to reflect respondents' support for individual responsibility. The second question is: "Some people think that the government in Washington ought to reduce the income differences between the rich and the poor, perhaps by raising the taxes of wealthy families or by giving income assistance to the poor. Others think that the government should not concern itself with reducing this income difference between the rich and the poor. What score between 1 and 7 comes closest to the way you feel?". Possible answers are "1 (Government should do something to reduce income differences), 2, 3, 4, 5, 6, 7 (Government should not concern itself with income differences)". Answers to this question reflect respondents' sympathy for income inequality and load positively in the first component of the first principal component analysis. Both questions have been simultaneously asked to GSS respondents only since 1983. The state level average of opposition to redistribution is higher in the West part of the Unites States over the period 1983-2010, which means the population living in these states is less favorable to collective redistribution.

We include individual observable characteristics as control variables in all regressions presented in the paper. Namely, we control for gender, age, age squared, marital status, religion, education, employment status, race and income. We also control for political

\footnotetext{
${ }^{7}$ In a earlier version of this paper (Couttenier and Sangnier 2012), the two questions are used as distinct dependent variables for most empirical results, in addition to a third question that is available for a smaller number of respondents.
} 
orientation - as questions we used to construct our measure of preferences for redistribution can also be simply associated to right-wing orientations - and trust in others - a belief that has been shown to be a major determinant of preferences for redistribution (see Rothstein and Uslaner 2005, Bergh and Bjørnskov 2011, and Bjørnskov and Svendsen 2013 among others). See Tables A1 and A2 in the Online Appendix for detailed definitions of individual covariates and their summary statistics. Once the availability of individual covariates is taken into account, we are left with about 20,000 respondents interviewed between 1983 and 2010 .

\subsection{Mineral resources}

The Mineral Resources Data System (MRDS) describes mineral resources throughout the world. ${ }^{8}$ The data set for the United States contains more than 25, 000 observations. About $50 \%$ of them have lead to the installation of a mine. For each observation, the data set contains information about the precise location, the year of discovery, the year of first production (if any production has been operated), and the type of commodities, but also various geologic characteristics. Missing information of major importance are those about quantities found and extracted.

The spatial distribution of mines in the United States is quite heterogeneous. Still, Western states have larger endowments in mineral resources than others. In the Online Appendix, Table A3 details the number of mines in each states. It distinguishes between all observations and places where a production was (or is still) operated. Both distributions are very similar. We use the simplest criterion to make the distinction between states according to mineral resources abundance: the median of the sample according to the number of mines. In regressions tables, the variable mineral state equals 1 if the respondent lives in a state with more mineral resources than the median US state, 0 if not. $^{9}$

Figure 1 displays the distribution of mineral resources discoveries in the United States over the 1800-2000 period. More than $75 \%$ of US mineral resources discoveries have been made between 1875 and the late '60s. Less than $1 \%$ of discoveries happened after the start year of GSS sample used in this paper. This leaves no room to identify any immediate or anticipated effect of discoveries on values held by contemporaneous GSS respondents.

Using MRDS observations to track the extent of mineral resources available in each state offers the advantage of being almost completely exogenous. Papyrakis and Gerlagh (2007) and Di Tella et al. (2010), among others, measure natural resources using the share

\footnotetext{
${ }^{8}$ The Mineral Resources Data System is edited by the US Geological Survey and available here: http://tin.er.usgs.gov/mrds.

${ }^{9}$ As shown by Table A4 in the Online Appendix, gold, silver and other valuable ores represent a substantial part of the mining activity in the United States. We conducted tests to check whether our results vary when taking into account the relative importance of specific ores in the ground. All empirical results presented in the paper do not depend on the precise type of mineral resources.
} 
of local GDP of a specific industrial sector and the price of commodities. This measure is clearly endogenous to economic activity and development, and consequently to attitudes provided that the latter have an effect on the former. In contrast, the tenor of the ground itself cannot be influenced by economic activity, nor by values. ${ }^{10}$

\subsection{Methodology}

Our sample is made of Americans interviewed in the GSS from 1983 to 2010. We first investigate the difference in preferences for redistribution between respondents living in states with large mineral resources endowment and those living in other states. We achieve this thanks to the estimation of the following expression:

$$
\text { Opposition to redistribution }{ }_{i}=\alpha+\beta M_{s(i)}+\gamma \mathbf{X}_{i}+\delta \mathbf{Z}_{t(i), s(i)}+\varepsilon_{i}
$$

where the dependent variable is our measure of opposition to redistribution for respondent $i$, interviewed at time $t$ and living in state $s$. The variable $M_{s(i)}$ is the dummy that indicates the mineral status of the state, labeled "mineral state" in regressions tables. $\mathbf{X}_{i}$ is a set of individual observable characteristics and $\mathbf{Z}_{t(i), s(i)}$ contains time fixed effects, as well as state-level variables or geographic characteristics in some specifications. Finally, $\varepsilon_{i}$ is the error term.

To uncover the persistence mechanisms - exposure and transmission-, we supplement expression (1) with a variable $M O_{s(i), b(i)}$ that is equal to 1 if there have been mineral resources discoveries in state $s$ during the life of an individual born on year $b$. It is labeled "mineral discoveries observed" in regressions tables. The GSS does not allow us to know in which state a respondent was living when she was young. However, we know if the respondent is still living in the same state as when she was 16 . This constrain us to restrict the sample to individuals that did not move between the two dates. This left us with around 14,000 individuals to estimate the following expression:

$$
\text { Opposition to redistribution }{ }_{i}=\alpha+\beta M_{s(i)}+\beta^{\prime} M O_{s(i), b(i)}+\gamma \mathbf{X}_{i}+\delta \mathbf{Z}_{t(i), s(i), b(i)}+\varepsilon_{i}
$$

where variables are defined as for expression (1), except that some specifications include covariates to control for individual and state characteristics during respondents' early years as illustrated by the subscript $b$ for vector $\mathbf{Z}$. Coefficient $\beta^{\prime}$ captures the exposure mechanism by comparing individuals who were exposed to a mineral resources discoveries

\footnotetext{
${ }^{10}$ One can however argue that the discovery of mineral resources is endogenous to economic development. This is very likely to be true. However, it is also possible that once economic development is launched, mineral resources are searched everywhere. Hence, on the one hand, the precise date of discovery of mineral resources can be seen as endogenous to economic activity. On the other hand, if we consider that all mineral resources have been searched for (as suggested by Figure 1 which shows that discoveries are scare since the late '60s), the categorization of states with and without mineral resources cannot be endogenous to values at the time of interview as the GSS sample we use starts in 1983.
} 
during their life to those that did not. Then, coefficient $\beta$ allows us to capture the transmission mechanism as the part of the overall relationship that is not mediated by the exposure to discoveries.

As the sampling of the General Social Survey is such that all states are not surveyed every year, all our estimations are performed using clustered standard errors at the state $\times$ year level. We estimate expressions (1) and (2) using ordinary least squares. ${ }^{11}$

Empirical evidence presented in this paper rely on comparisons across states. But information about longitude and latitude of mineral resources may suggest a within state analysis. However, such an approach is hardly feasible because of one major stumbling block. It is only possible to gather information for the GSS on 300 out of nearly 3,000 US counties. Unfortunately, these counties are geographically clustered within each state. As a consequence, there is virtually no variation in mineral resources endowment between counties of the same state. This makes a county-level analysis impossible to implement given the structure of the data.

An implicit assumption that we make when estimating the above relationships is that the effect of mineral resources abundance or discovery is the same across state. A key point that may invalidate this assumption is the heterogeneity of mining laws across states. Indeed, the initial formation as well as the transmission of values could be different depending on the legislative environment. However, mining law appears to be remarkably homogeneous across states. Although marginally amended since the late $19^{\text {th }}$ century, the General Mining Act of 1872 is still the main law used to regulate mining prospection in the United States. This law codifies the way individuals may claim property rights on deposits and subsequent rights and duties. It applies the same way everywhere in the United States. This law encompasses the first laws of 1866 and 1870, as well as the informal regulation system for the acquisition and the protection of mines set up by the first prospectors. In addition, the informal system itself was virtually identical across places. See Braunstein (1985) and Mayer (1986) for more details.

\section{Empirical results}

In this section we first compare individuals living in states with large mineral resources endowment to those living in states without large mineral resources endowment. We also propose strategies to test the robustness of this correlation. Then, we uncover the persistence mechanisms. Finally, we further discuss our results.

\footnotetext{
${ }^{11}$ In Couttenier and Sangnier (2012), we use ordered logit and probit models to estimate expressions (11) and (2) when answers to questions are used as dependent variables instead of their first principal component.
} 


\subsection{Main result}

We first start by a simple test of equality of the means of our measure of opposition to redistribution across states with and without mineral resources. Table 1 presents the standard t-tests for our variable of interest - opposition to redistribution - and for the two variables used in the first principal component analysis. In all cases, the average answer is higher in states with mineral resources than in states without mineral endowments.

We estimate expression (11) with individual characteristics to assess whether aggregate differences are driven by composition effects. Our baseline specification includes usual control variables for gender, age, age squared, marital status, religion, education, employment status, race, income, political orientation and trust, as well as fixed effects for the year of interview. The latter absorb common temporal determinants of attitudes. Estimated coefficients are presented in the first column of Table 2, The estimated coefficient of the dummy variable for individual living in states with mineral resources is positive and statistically significant. Estimated coefficients of individual covariates are consistent with those presented by other scholars (see Alesina and La Ferrara 2005 among others).

The estimated coefficient of our variable of interest is equal to 0.074. We compare it to the variance of the dependent variable to establish the economic significance of our result. The standard deviation of the dependent variable is 1.17 , which means that "moving" from a non-mineral to a mineral state is associated with an increase in opposition to redistribution that amounts about $6 \%$ of this variable's standard deviation. This apparently modest effect should be compared to those of other determinants of individualism. For instance, the coefficient associated to the protestant affiliation equals 0.098, the reference being "none/other". The estimated effect of being married equals 0.153. Accordingly, the contribution of our variable of interest is about half as important as the one of matrimonial status and almost as important as the one of religion.

All in all, this regression shows that the difference in the preferences for redistribution between states with or without mineral resources is not driven by a composition effect of the populations surveyed, i.e. individuals living in mineral states do not systematically share observable characteristics that favor such attitudes; and that this difference is economically relevant.

\subsection{Robustness checks}

In this sub-section, we perform a number of tests that challenge the robustness of our main result. In particular, we pursue a number of strategies to determine whether the correlation we uncover is driven by omitted variables or by selection biases. 


\section{State-level and individual omitted variables}

The positive effect of mineral endowment on opposition to redistribution could be contaminated by state-level omitted variables. The second column of Table 2 displays estimated coefficients when adding the following state-level variables to our specification: region fixed effects, longitude of the state capital, population density, state per capita income, and the state coefficient of Gini. All are defined at the time of interview, except region fixed effects and longitude which are time-invariant. See Table A1 in the Online Appendix for the sources and detailed definitions of state-level covariates.

The rationale to take geography into account is that the spatial distribution of mining activity in the United States is broadly polarized between West and East. Hence, the correlation could be driven by simple omitted variables linked to common characteristics of geographically close states. We thus include three region fixed effects that correspond to the four regions defined by the US Census Bureau: Northeast, Midwest, South and West. The inclusion of the longitude of the state capital further control for the East-West alignment of states. Diamond (2006) writes that "Montanans tend to be conservative, and suspicious of governmental regulation. That attitude arose historically because early settlers were living at low population density [...]". The geographical conditions of Montana, in which many mineral discoveries took place, induces a very low population density which could explain the attitudes of citizens and more particularly why individuals in this state are more opposed to collective redistribution. This advocates for considering population density as a candidate omitted variable. Finally, income per capita and Gini coefficient in the state at the time of interview further help us to control for differences in aggregate wealth and inequalities.

The simultaneous inclusion of all the above mentioned variables does not harm the estimated coefficient of our variable of interest. This makes us confident that the effect of the mineral status is not totally driven by state-level omitted variables.

Yet, our result could also be driven by omitted individual variables. Two appealing candidates variables are individuals' cultural origin and their occupation. As pointed out by Grosjean (2014) among others, Americans from different origins hold different values. We thus construct fixed effects that correspond to the individual's ancestors country. ${ }^{12}$ It is also likely that the composition of occupations within states determines part of differences in individualism. Hence, we introduce industry fixed effects. ${ }^{13}$ The third column of Table 2 presents the estimated coefficient of our variable of interest when origin and industry fixed effects are included as covariates. The estimated coefficient of the mineral status is unaltered by the introduction of this set of variables.

\footnotetext{
${ }^{12}$ The question asked in the GSS is: "From what countries or part of the world did your ancestors come?".

${ }^{13}$ Unfortunately, the GSS sampling is such that the number individuals working precisely in the mining industry represents less than $0.5 \%$ of the sample. This makes impossible to draw any particular results for this specific category of respondents.
} 
All state-level variables, as well as ancestors country and industry fixed effects, are used as covariates in the regression presented in the last column of Table 2. Again, our main estimated coefficient is positive and statistically significant. ${ }^{14}$

\section{Alternative measures of mineral abundance}

In Table 3, we propose five alternative measures of mineral abundance in a state. We first use three logarithmic proxies of the abundance of mineral resources by state: the log of 1 plus (i) the number of mines, (ii) the number of mines per inhabitant, and (iii) the number of mines per square miles. Second, we take inspiration from Persson and Tabellini (2009) and compute the discounted sum of mines discovered in a state throughout history as:

$$
\text { Discounted number of mines } s=\sum_{t=0}^{t=T} \mathbb{M}_{s t} \frac{1}{1+\delta(T-t)},
$$

where $\mathbb{M}_{s t}$ is the number of mineral resources discoveries in state $s$ on year $t$, and $T$ is arbitrarily set to 2010 . We use $5 \%$ and $10 \%$ as candidate values for the yearly discount factor $\delta$.

Each cell of Table 3 presents the estimated coefficient of one of these alternative measures of mineral abundance. Coefficients displayed in column 1 are those obtained when only individual covariates are included in the regression. Coefficients presented in column 2 are those obtained when state-level covariates are introduced as covariates, together with origin and industry fixed effects. All these alternative measures have a positive effect on opposition to redistribution, except for the number of mines per square mile that turns out to be non-statistically significant when all covariates are used simultaneously.

\section{Selection}

The relationship documented in this paper could be driven by selection, i.e. individuals that are opposed to redistribution could have been attracted by the spirit that prevails in mineral states, or by the opportunities offered by these states. Similarly, that specific spirit may have push individuals who do not share it to move out. We can identify two issues related to the selection effect.

The first issue concerns today's self-selection. It is possible that people who support redistribution move out of mineral state. Symmetrically, individuals who are opposed to redistribution could be attracted to mineral states. By construction, this two kinds of

\footnotetext{
${ }^{14}$ As shown by the comparison between the four columns of Table 2 the introduction of state-level variables and further individual variables changes the size of the coefficient of our variable of interest. The relative importance of this change can be used to asses the potential omitted variable bias as suggested by Altonji et al. (2005). We implement this approach in the Online Appendix. It confirms that it is unlikely that supplementary omitted variables drive the result presented here. We also show in the Online Appendix that the correlations we uncover are far from spurious thanks to two falsification exercises by which we randomize the mineral status of states.
} 
migration would mechanically foster opposition to redistribution in mineral states. We test both mechanisms by creating a variable that indicates whether a respondent has changed state since she was 16 years old and interacting it with the mineral status of the state where she lives when interviewed. Estimating such a variation of expression (1) provides us with estimates and test statistics that do not support the hypothesis that the relationship between the mineral status of the state and opposition to redistribution is driven by recent selection effects. ${ }^{15}$

The second issue is linked to initial selection of inhabitants into mineral states. Geographic and economic conditions can lead to a selection of inhabitants across immigration and settlement destinations. Mineral discoveries in the mid- $19^{\text {th }}$ century may have attracted individuals characterized by specific traits. Such individuals are likely to be characterized by a very small risk aversion, very developed entrepreneurship values, and ex ante aversion for redistribution or public intervention in the economic activity. ${ }^{16}$ Settlement of such pioneers - endowed with particular traits - would then launch the transmission of values to next generations. The values observed in the late $20^{\text {th }}$ century would thus originate from a transmission of values from people who were opposed to redistribution before their arrival in mineral states. From a purely statistical point of view, significance of our variable of interest would have already disappeared when using origin country fixed effects in table 2 if initial selection was the main driver of the relationship. However, it is worth investigating if we can find any support for this hypothesis.

Reversing the epidemiological approach used in cultural economics can help us to do so. Following this approach, Americans inherited attitudes toward various subjects that reflect the culture of their ancestors' origin country. If initial selection took place, then American immigrants from countries whose citizens are more opposed to redistribution should have be more likely to settle in mineral states. A direct test of this hypothesis requires precise information about the origin of early settlers in the United States. Such information would allow us to check whether there is systematic variations in origin countries among individuals who settled in mineral or non-mineral states. Early information about origin countries are scarce. As noted by Grosjean (2014), early US Census data list only few different origin countries. We thus directly use information provided by the General Social Survey about ancestors' countries. Some origins are well-balanced across mineral and non-mineral states. For example, the population of Americans with French

\footnotetext{
${ }^{15}$ The relevant estimates are: Opposition to redistribution $=\underset{(0.021)}{0.089^{* * *}}$ Mineral state $\underset{(0.027)}{0.046^{*}}$ Mover $\underset{(0.036)}{0.053}$ Mineral state $\times$ Mover $+\ldots$

where coefficients of other covariates are not reported, standard errors are presented in parentheses, * indicates statistical significance at the $10 \%$ level, and ${ }^{* *}$ indicates statistical significance at the $1 \%$ level. Mineral state is equal to 1 if the respondent lives in a state with more mineral resources than the median US state, 0 if not. Mover is equal to 1 if the respondent does not live in the same state as when it was 16 years old.

${ }^{16}$ See Clay and Jones (2008) about the selection on observable characteristics during the Gold Rush.
} 
or Italian ancestors is almost equally balanced across the two groups of states. However, strong differences appear across other origins. For example, 83 percents of Americans with Finnish ancestors live in non-mineral states. On the opposite, 86 percents of respondents with Spanish ancestors live in mineral states. These differences in allocation across origins speak to the initial selection hypothesis.

However, a complete validation of this hypothesis necessitates that individuals whose culture is more opposed to redistribution settled in mineral states. In other terms, the lower opposition to redistribution in a given origin country, the higher should be the share of Americans from this country who initially migrated to mineral states. To check this, we proxy opposition to redistribution in a set of origin countries by a question from the World Values Survey (WVS) that is very close to the GSS question about the support for individual responsibility: "Now I'd like you to tell me your views on various issues. How would you place your views on this scale? 1 means you agree completely with the statement on the left; 10 means you agree completely with the statement on the right; and if your views fall somewhere in between, you can choose any number in between. People should take more responsibility to provide for themselves versus The government should take more responsibility to ensure that everyone is provided for." We reverse the scale of answers such that answers reflect increasing support for individual self-responsibility. Information available in the GSS and in the WVS allow us to construct Figure 2(a) that presents the positive relationship between the support for individual responsibility in origin countries and the support for individual responsibility among Americans of first and second generations from 28 different origins.

We then check whether Americans originating from countries that support more individual responsibility are more likely to be found in mineral states. To achieve this, we plot the share of individuals from different origins that live in these states against the average support for individual responsibility in their ancestors' country. We expect initial selection to show up under the form of a increasing relationship between both variables. As shown by Figure 2(b), the relationship is not increasing. If anything, the relationship is decreasing. Such an interpretation would go against the initial selection hypothesis. In other words, the share of Americans of a given origin living in mineral states is not increasing as support for individual responsibility in their origin country increases. Although coarse because indirect, this approach does not support the hypothesis of initial selection of Americans pioneers into mineral rich environments along opposition to redistribution.

\subsection{Mechanisms of belief acquisition}

Results presented so far illustrate the importance of mineral resources to the preferences for redistribution. In the introduction, we stressed two potential mechanisms through which values develop at the individual level. The exposure mechanism is linked to the 
direct effect of mineral resources on the preferences for redistribution. It is based on the idea that values depend on events that happened during the life of an individual. Hence, the exposure to "shocks" on mineral resources abundance is likely to shape ones' values. The transmission mechanism refers to the question of transmission and persistence of beliefs. It occurs within the society, across and within generations. We take advantage of the distribution of mineral resources discoveries across time to show that the exposure mechanism matters but is insufficient to fully explain the overall relationship between mineral resources and opposition to redistribution. The space that is left by the exposure mechanism creates room for the transmission mechanism. The latter is uncovered by comparing individuals who were not exposed to mineral discoveries since their birth - e.g. because they are born after the last discovery - to individuals that also live in mineral resources rich states but for whom mineral resources discoveries occurred during their life. $^{17}$

Estimated coefficients of equation (2) are presented in Table 4. The two variables of interest are the one that indicates whether an individual lives in a states with lots of mineral resources and the one that indicates whether some discoveries occurred in that state since the respondent is born. Both reveal positive and statistically significant effects when we control for individual- and state-level covariates, as well as origin and industry fixed effects as shown by columns 1 and 2. This means that individuals who are born after the last year of discoveries in the state are more opposed to redistribution than people leaving in non-mineral states and that respondents that are likely to have been exposed to discoveries during their life are themselves more opposed to redistribution than the former. This result uncovers the exposure mechanism and reveals the role of transmission of preferences for redistribution in mineral states.

The identification of the mechanisms is robust to the introduction of a large set of covariates (columns 3 and 4 of Table 4). Namely, we control for birth year thanks to birth cohort fixed effects and for respondent's past situation by introducing family and state per capita income when the respondent was 16 years old. ${ }^{18}$ The estimated coefficients of interest remain positive and statistically significant at the conventional level with the inclusion of all covariates simultaneously (column 5).

Coefficients presented in Table 4 allow us to assess the relative importance of the two mechanisms. A back-of-the-envelope calculation leads to the following conclusion:

\footnotetext{
${ }^{17}$ Another way to uncover this mechanism would be to exploit a natural experiment as in Di Tella et al. (2007). Unfortunately, it is impossible to implement such a methodology because of the nature of our data. As we pointed out in section 2, mineral discoveries occurs in the US until the late 60's, while data we used to measure opposition to redistribution are available only since the mid-80's. Moreover, the GSS does not provide information on the city of birth but only if the respondent was living in the same state when it was 16 years old. While this information allowed us to tackle the migration issue, it is a strong limit to the implementation of a natural experiment.

${ }^{18}$ Past family income is the answer, on a 5-item scale, to the following question: "Thinking about the time when you were 16 years old, compared with American families in general then, would you say your family income was far below average, below average, average, above average, or far above average?".
} 
the exposure mechanism accounts for about $35 \%$ of the overall difference in preferences for redistribution between mineral and non-mineral states. ${ }^{19}$ The remaining $65 \%$ are accounted for by the transmission mechanism.

\subsection{Discussion}

In this sub-subsection, we further discuss empirical results. We fist compare them to the literature's closest contributions. We then propose a sensitivity test for our result about the exposure to mineral resources discoveries.

\section{Values associated to mineral discoveries}

As already stressed in the introduction, we argue that the initial effect of mineral resources' abundance on preferences for redistribution is likely to be driven by some income effect. However, as shown by estimates presented in Table 2 , the introduction of individual income levels and state per capita income leaves the estimated coefficient of our main variable of interest positive and significant. This suggests that the effect of mineral resources does not transit only through current income but stems from some historical process. In Table 4 , we also control for past state per capita income and for respondents' childhood income level. The fact that the positive relationship between mineral resources abundance and opposition to redistribution persists when all these income variables are included in regressions reinforces the feeling that while a part of the (initial or perpetuated) effect is likely to transit through income, something else is at play. Mineral resources are associated with opposition to redistribution because of specific features they bear that are not limited to their transaction value. In other words, mineral resources are not only valuable but also associated with particular values.

The above remark also relates to the fact that our main result is differing from those of Di Tella et al. (2010). These authors show that there is a negative correlation between opposition to redistribution and oil in the United States. A first explanation of the apparent divergence between our finding and those by Di Tella et al. (2010) is that oil and mineral resources have different characteristics. Boschini et al. (2007) argue that the effect of natural resources' abundance on economic performance depends on the precise types of resources owned. These scholars point out the role of resource's appropriability, a concept that "captures the likelihood that natural resources lead to rent-seeking, corruption or

\footnotetext{
${ }^{19}$ The back-of-the-envelope calculation is as follows. The contribution of the exposure mechanism to the overall difference is equal to the share of individuals being exposed to mineral discoveries during their life-time (0.36 according to Table A2 presented in the Online Appendix) multiplied by the coefficient of the variable mineral discoveries observed from Table 4 . The overall effect is the sum of the exposure mechanism plus the coefficient of the variable mineral state from Table 4 . According to estimates presented in column 1 , the contribution of the exposure mechanism is $\frac{0.36 \times 0.072}{0.049+0.36 \times 0.072} \approx 35 \%$. Using estimates from columns $2-5$, the contribution of the exposure mechanism is $28 \%, 41 \%, 42 \%$, and $32 \%$ respectively. Thus, the median contribution across the five columns of Table 4 is $35 \%$.
} 
conflicts which, in turn, harm economic development" and largely refers to resources' concrete characteristics. Mineral resources in general, and gold and silver in particularthat represents close $50 \%$ of US exploited mines according to MRDS data-, are more appropriable than oil. Mineral resources are also intrinsically more valuable, transportable and storable. These differences in resources' characteristics imply important differences in technologies. For instance, mineral resources exploitation is more labor intensive than oil production. This is supported by anecdotal evidence that mining was very labor intensive in the early times of the development of mining industry, as reported in the introduction. Still today, mining is more labor intensive that oil extraction: according to data from the Bureau of Economic Analysis for the period 1998-2009, the mining industry is twice more labor intensive that the oil and gas extraction industry.

Such discrepancy in the use of labor between both industries is likely to be correlated with efforts that are necessary to exploit resources. Efforts an individual puts in production are themselves a key determinant of ones's support for individual responsibility. Indeed, the greater the feeling that luck instead of hard work determines income, the larger the support for collective redistribution. Symmetrically, if an individual thinks that income is primarily determined by individual effort, she will exhibit less willingness to redistribute and support more individual responsibility. This is precisely the argument of Di Tella et al. (2010) who argue that revenues from the oil industry are a proxy for luck at the state level which, in turn, influences the demand for redistribution of individuals. A similar mechanism is put forward by Davis (2014) who document a negative relationship between rainfall variation and individual responsibility.

It turns out that mineral resources abundance is not positively associated with the belief that luck is an important determinant of ones' success in life. In fact, it is quite the opposite. The GSS question about the sources of success helps us to show this by using it as alternative dependent variable in expression (1). Estimating such an expression produces a positive and statistically significant relationship between mineral resources and the belief that hard work is more important than lucky breaks. ${ }^{20}$ This means that the feeling that success is determined by hard work is spread more widely in states with mineral resources than in other states. So, in contrast to oil, mineral resources abundance is negatively correlated with the belief that luck is the most important determinant of success. This also speaks to the mythology of mining as an activity that pays off only

${ }^{20}$ The relevant estimate is:

$$
\text { Hard work }=\underset{(0.013)}{0.023^{*}} \text { Mineral state }+\ldots
$$

where coefficients of other covariates are not reported, the standard error is presented in parentheses, and * indicates statistical significance at the $10 \%$ level. Mineral state is equal to 1 if the respondent lives in a state with more mineral resources than the median US state, 0 if not. Hard work is the reversed answer to the following question: "Some people say that people get ahead by their own hard work; others say that lucky breaks or help from other people are more important. Which do you think is most important?". 
after painful and dangerous work.

\section{Age-windows exposure to discoveries and opposition to redistribution}

We undertook a rather agnostic approach by choosing a respondent's entire life as the period during which she is able to observe mineral resources discoveries. Other scholars have a different approach. For example, Giuliano and Spilimbergo (2014) argue that individuals exposed to an economic recession when aged between 18 and 25 have different beliefs. Their approach relies on the "impressionable years" hypothesis which states that "core attitudes, beliefs, and values crystallize during a period of great mental plasticity in early adulthood and remain largely unaltered throughout the remaining adult years". Giuliano and Spilimbergo (2014) build on the intuition that impressionable years are relevant because under 18 individuals are not able to understand the complexity of the economy, and after 25 their preferences are harder to change. In the case of mineral resources discoveries, the relevant time period of influence could be different. To investigate this question, we consider all candidate age-windows. For every starting age $s \in[1,50]$ and end age $e \in[s, 80]$, we construct a variable that indicates whether mineral resources occurred in the state where the respondent is living when she was aged between $s$ and $e$. We then re-estimate equation (2) supplemented by this variable and plot the new variable test statistic in Figure $3{ }^{21}$ This heat map shows that the estimated coefficient of the variable that indicates potential observation of discoveries is significant at the $5 \%$ significance level in about $50 \%$ of the cases when the starting age is below 21 . In contrast, all estimates show non-statistically significant if the starting age is larger than 21. More generally, the test statistic is decreasing with the starting age. Another feature of the resulting distribution that is perceptible by visual observation is that, conditional on starting or end age, statistics are increasing in the size of the observation-window. All in all, this approach provides evidence that exposure is relevant for many windows and not only for the "impressionable years" period, at least regarding mineral resources discoveries.

\section{Conclusion}

In this paper, we take advantage of geo-referenced information on mineral resources' discoveries in United States over the 1800-2000 period to provide evidence that mineral resources abundance is associated with opposition to redistribution. We perform numerous sensitivity tests and show that our results are robust to a variety of alternative

\footnotetext{
${ }^{21}$ Figure 3 corresponds to estimates of equation (2) with only baseline individual covariates. We would obtain a virtually identical figure if we were to use those obtained when all covariates are used, as in the fifth column of Table 4 .
} 
specifications, addressing concerns related to omitted variable bias, selection effects, and the way we construct our variable of interest.

We uncover two mechanisms through which opposition to redistribution induced by mineral resources abundance develops and persists at the individual level. First, we stress that attitudes depend on events that happened during the life of an individual, which means that the exposure to mineral discoveries shapes individuals' values. Respondents that have been exposed to mineral resources discoveries over their life-time are more opposed to redistribution than others. Second, we uncover a transmission mechanism that corresponds to values transmitted by peers. Individuals who are born after a state's last mineral resources discoveries are more opposed to redistribution than people leaving in non-mineral states. A back-of-the-envelope calculation help us to state that the exposure mechanism accounts for about $35 \%$ of the overall difference in individualism between mineral and non-mineral states.

All in all, empirical evidence presented in this paper suggest that mineral resources are associated with particular characteristics that go beyond their mere transaction value. Among these characteristics, it is worth noting the role of effort in the exploitation of mineral resources as suggested by the narrative of American mining history. The role of effort is also a dimension that distinguishes our finding on mineral resources from those of other scholars about the relationship between taste for redistribution or collectivism and oil revenues or agricultural shocks. 


\section{References}

Alesina, Alberto, and George-Marios Angeletos. "Fairness and Redistribution." American Economic Review 95, 4: (2005) 960-980.

Alesina, Alberto, and Paola Giuliano. "Preferences for Redistribution." In Handbook of Social Economics, edited by Alberto Bisin Jess Benhabib, and Matthew O. Jackson, North-Holland, 2011, volume 1, 93 - 131.

Alesina, Alberto, and Eliana La Ferrara. "Preferences for redistribution in the land of opportunities." Journal of Public Economics 89, 5-6: (2005) 897-931.

Altonji, Joseph G., Todd E. Elder, and Christopher R. Taber. "Selection on Observed and Unobserved Variables: Assessing the Effectiveness of Catholic Schools." Journal of Political Economy 113, 1: (2005) 151-184.

Bergh, Andreas, and Christian Bjørnskov. "Historical Trust Levels Predict the Current Size of the Welfare State." Kyklos 64, 1: (2011) 1-19.

Bisin, Alberto, and Thierry Verdier. "The Economics of Cultural Transmission and the Dynamics of Preferences." Journal of Economic Theory 97, 2: (2001) 298-319.

- "Cultural transmission." In The New Palgrave Dictionary of Economics, edited by Steven N. Durlauf, and Lawrence E. Blume, Palgrave Macmillan, 2008.

Bjørnskov, Christian, and Gert Svendsen. "Does social trust determine the size of the welfare state? Evidence using historical identification." Public Choice 157, 1: (2013) 269-286.

Boschini, Anne D., Jan Pettersson, and Jesper Roine. "Resource Curse or Not: A Question of Appropriability." Scandinavian Journal of Economics 109, 3: (2007) 593-617.

Braunstein, Michael. "Natural Environments and Natural Resources: An Economic Analysis and New Interpretation of the General Mining Law." UCLA Law Review 32: (1985) 1133-1202.

Clay, Karen, and Randall Jones. "Migrating to Riches? Evidence from the California Gold Rush." The Journal of Economic History 68, 04: (2008) 997-1027.

Couttenier, Mathieu, and Marc Sangnier. "Living in the Garden of Eden: Mineral Resources Foster Individualism." Cahiers de Recherches Economiques du Département d'Econométrie et d'Economie politique (DEEP) 12.05, Université de Lausanne, Faculté des HEC, DEEP, 2012. 
Davis, Lewis. "Individual Responsibility and Economic Development: Evidence from Rainfall Data." Technical Report 1746884, Available at SSRN, 2014.

Di Tella, Rafael, Juan Dubra, and Robert MacCulloch. "A Resource Belief-Curse? Oil and Individualism." In The Natural Resources Trap: Private Investment without Public Commitment, edited by William Hogan, and Federico Sturzenegger, Cambridge, Mass.: MIT Press, 2010.

Di Tella, Rafael, Sebastian Galiani, and Ernesto Schargrodsky. "The Formation of Beliefs: Evidence from the Allocation of Land Titles to Squatters." The Quarterly Journal of Economics 122, 1: (2007) 209-241.

Diamond, Jared. Collapse: How Societies Choose to Fail or Succeed. Penguin Books, 2006.

Durante, Ruben. "Risk, Cooperation and the Economic Origins of Social Trust: an Empirical Investigation." MPRA Paper 25887, University Library of Munich, Germany, 2009.

Fernández, Raquel. "Does Culture Matter?" In Handbook of Social Economics, edited by Alberto Bisin Jess Benhabib, and Matthew O. Jackson, North-Holland, 2011, volume 1, $481-510$.

Freudenburg, William R., and Scott Frickel. "Digging Deeper: Mining-Dependent Regions in Historical Perspective." Rural Sociology 59: (1994) 266-288.

Friedman, Gerald. "U.S. Historical Statistics: New Estimates of Union Membership the United States, 1880-1914." Historical Methods: A Journal of Quantitative and Interdisciplinary History 32: (1999) 75-86.

Giuliano, Paola, and Antonio Spilimbergo. "Growing Up in a Recession: Beliefs and the Macroeconomy." Review of Economic Studies 81: (2014) 787-817.

Glaeser, Edward L., Sari Pekkala Kerr, and William R. Kerr. "Entrepreneurship and Urban Growth: An Empirical Assessment with Historical Mines." Review of Economics and Statistics forthcoming.

Grosfeld, Irena, Alexander Rodnyansky, and Ekaterina Zhuravskaya. "Persistent Antimarket Culture: A Legacy of the Pale of Settlement after the Holocaust." American Economic Journal: Economic Policy 5, 3: (2013) 189-226.

Grosjean, Pauline. "A History of Violence: The Culture of Honor as a Determinant of Homicide in the US South." Journal of the European Economic Association 12, 5: (2014) 1285-1316. 
Guiso, Luigi, Paola Sapienza, and Luigi Zingales. "Long Term Persistence." NBER Working Papers 14278, National Bureau of Economic Research, Inc, 2008.

Luttmer, Erzo F. P., and Monica Singhal. "Culture, Context, and the Taste for Redistribution." American Economic Journal: Economic Policy 3, 1: (2011) 157-79.

Mayer, Carl J. "The 1872 Mining Law: Historical Origins of the Discovery Rule." The University of Chicago Law Review 53, 2: (1986) 624-653.

Meltzer, Allan H, and Scott F Richard. "A Rational Theory of the Size of Government." Journal of Political Economy 89, 5: (1981) 914-27.

Nunn, Nathan, and Leonard Wantchekon. "The Slave Trade and the Origins of Mistrust in Africa." American Economic Review 101, 7: (2011) 3221-52.

Papyrakis, Elissaios, and Reyer Gerlagh. "Resource abundance and economic growth in the United States." European Economic Review 51, 4: (2007) 1011-1039.

Persson, Torsten, and Guido Tabellini. "Democratic Capital: The Nexus of Political and Economic Change." American Economic Journal: Macroeconomics 1, 2: (2009) 88-126.

Piketty, Thomas. "Social Mobility and Redistributive Politics." The Quarterly Journal of Economics 110, 3: (1995) 551-84.

Rickard, T. A. A history of American Mining. McGraw-Hill Book Company, Inc., 1932.

Riley, Nicola-Maria. "Determinants of Union Membership: A Review." Labour 11, 2: (1997) 265-301.

Romer, Thomas. "Individual welfare, majority voting, and the properties of a linear income tax." Journal of Public Economics 4, 2: (1975) 163-185.

Rothstein, Bo, and Eric M. Uslaner. "All for All: Equality, Corruption, and Social Trust." World Politics 58, 1: (2005) 41-72.

Schnabel, Claus. "Determinants of trade union membership." In International Handbook of Trade Unions, edited by John T. Addison, and Claus Schnabel, Cheltenham, UK: Edward Elgar, 2003.

Schnabel, Claus, and Joachim Wagner. "Union density and determinants of union membership in 18 EU countries: evidence from micro data, 2002/031." Industrial Relations Journal 38, 1: (2007) 5-32. 
Figure 1: Distribution of mineral resources discoveries in the United States (1800-2000).

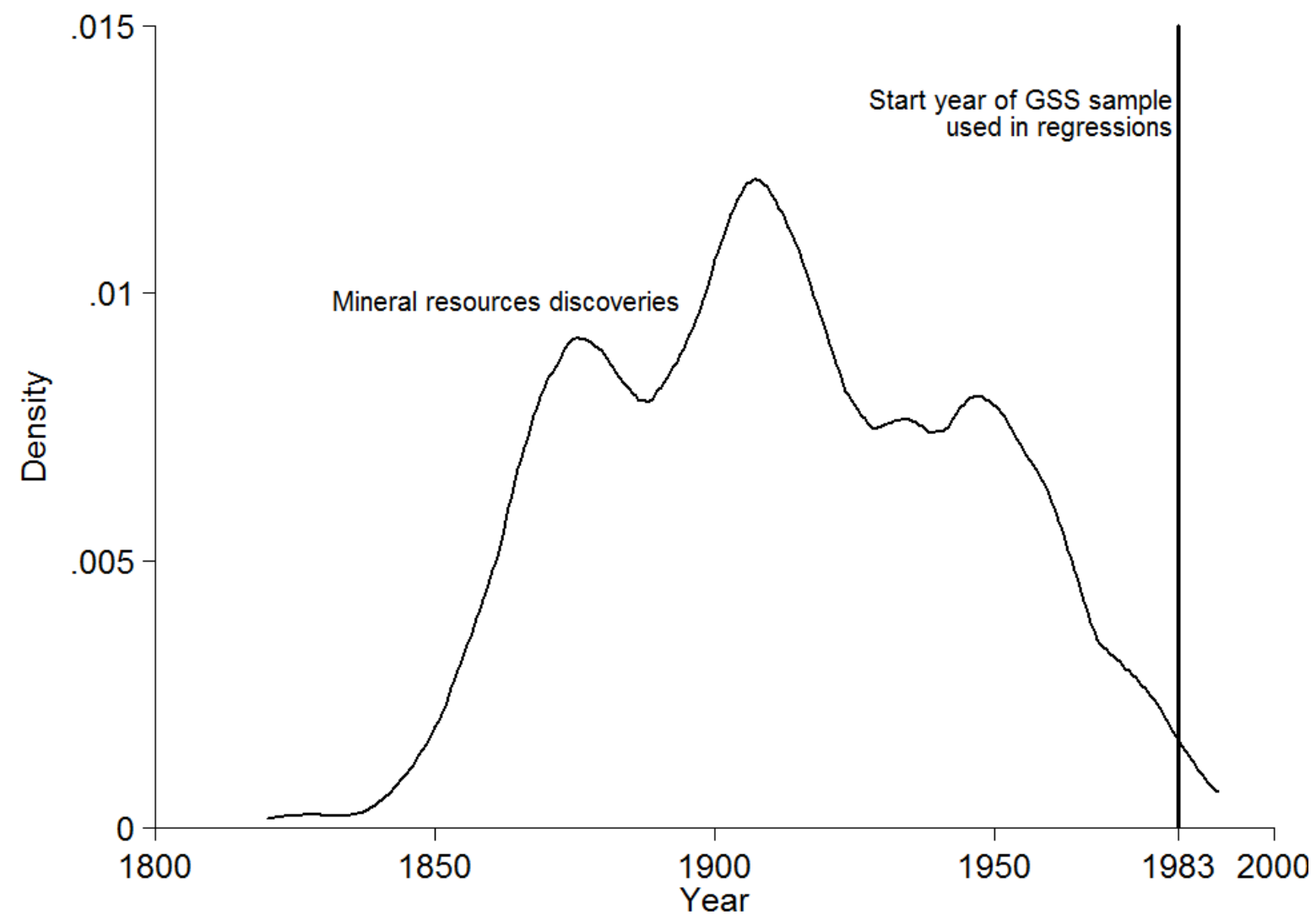

Source: Mineral Resources Data System. 
Figure 2: Relationship between the support for individual responsibility in origin countries and the support for individual responsibility among first and second generations Americans; and relationship the support for individual responsibility in origin countries and the share of individuals living in mineral rather than non-mineral states.

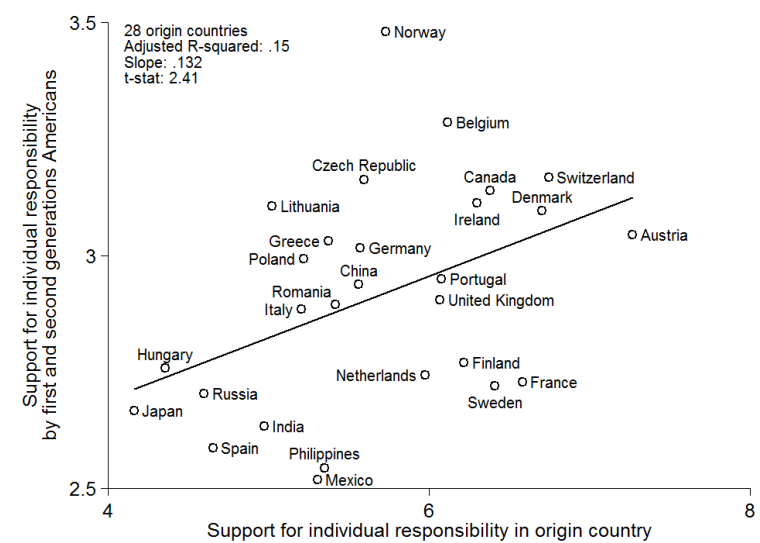

(a) Relationship between the support for individual responsibility in origin countries and the support for individual responsibility among first and second generations Americans.

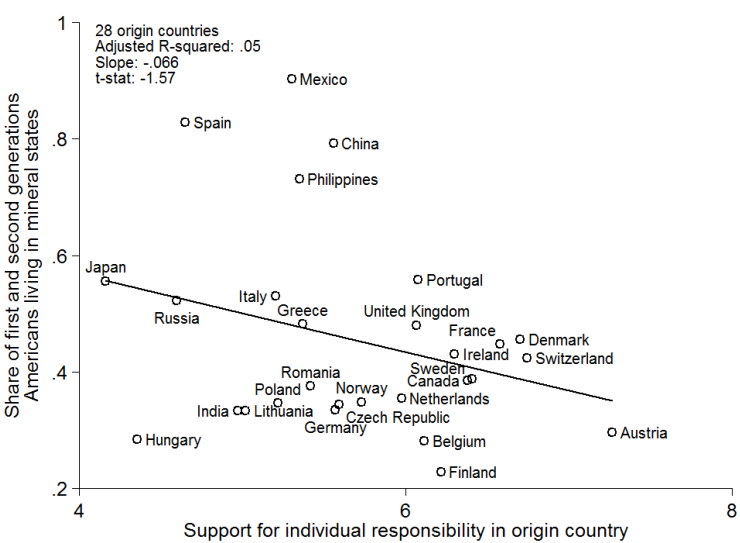

(b) Relationship the support for individual responsibility in origin countries and the share of individuals living in mineral rather than non-mineral states.

Sources: General Social Survey and World Values Survey. Each respondent's origin country is determined from the answer to the following question: "From what countries or part of the world did your ancestors come?". The support for individual responsibility among Americans is constructed using first and second generations Americans. The support for individual responsibility in origin country is constructed using the average answer by country to the following question from the World Values Survey: "Now I'd like you to tell me your views on various issues. How would you place your views on this scale? 1 means you agree completely with the statement on the left; 10 means you agree completely with the statement on the right; and if your views fall somewhere in between, you can choose any number in between. People should take more responsibility to provide for themselves versus The government should take more responsibility to ensure that everyone is provided for." The scale of answers is reversed such that answers reflect increasing support for individual self-responsibility. The share of individuals living in mineral states is the share of individuals from the same origin that live in a state with more mineral resources than the median US state. 
Figure 3: Test statistics of the effect of having observed mineral discoveries within different age-windows.

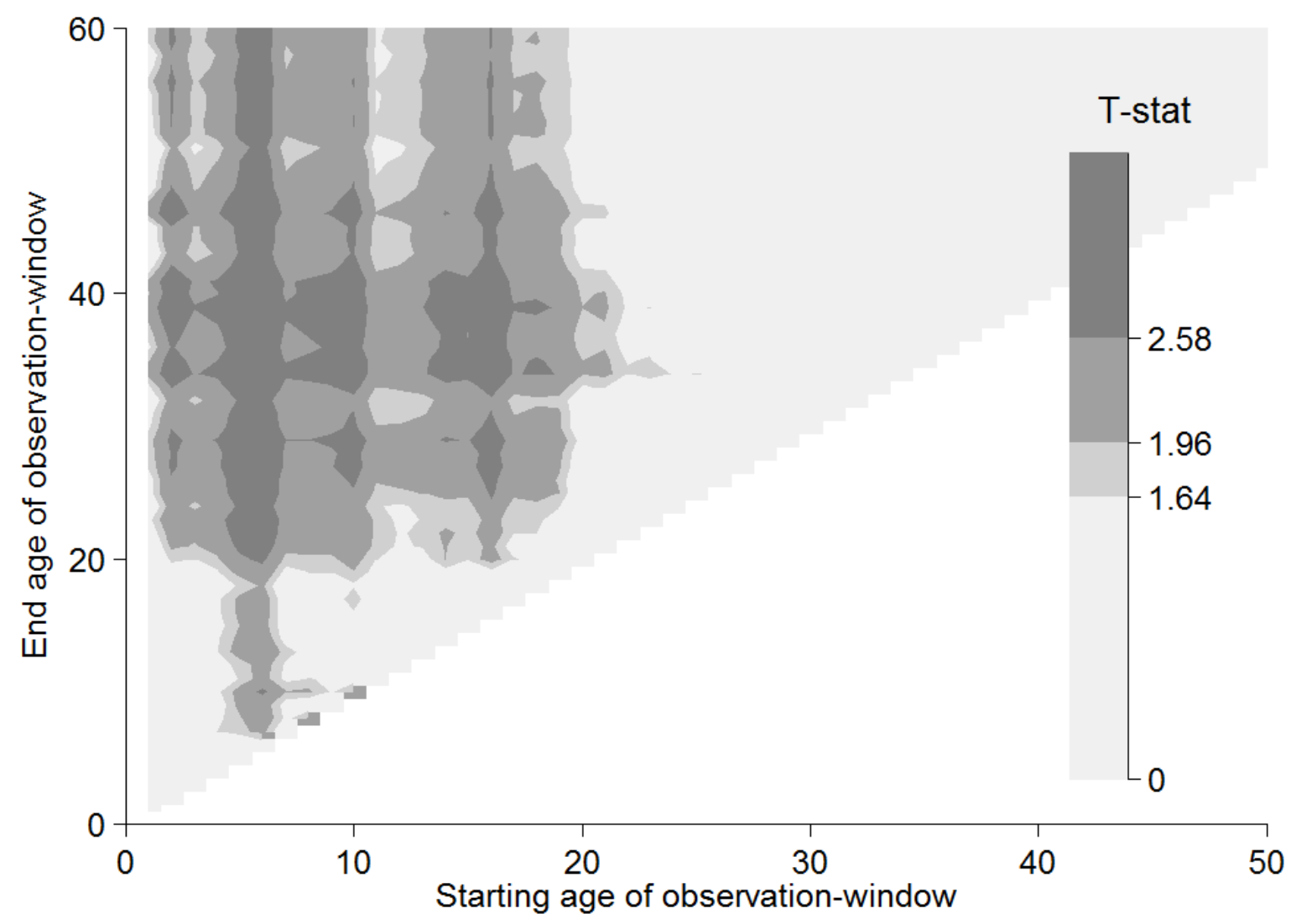

The figures plots the test statistic of the estimated coefficient of being exposed to mineral discoveries within different agewindows. Statistics have been obtained by estimating the same expression as the one presented in column 1 of Table 4 with the addition of a variable that is equal to 1 if there have been mineral discoveries in the state where the respondent is living when the she was aged between $s$ and $e$, where all possible combinations of $s \leq e$ have been used sequentially. 
Table 1: Mean-comparison tests.

\begin{tabular}{lccr}
\hline \hline & Non-mineral states & Mineral states & P-value of t-test \\
\cline { 2 - 4 } \# of observations & 10,035 & 10,158 & \\
& & & \\
Opposition to redistribution & $-0.02(1.15)$ & $0.05(1.19)$ & 0.00 \\
Support for individual responsibility & $2.90(1.15)$ & $2.92(1.17)$ & 0.17 \\
Sympathy for income inequality & $3.66(1.92)$ & $3.81(1.97)$ & 0.00 \\
\hline \hline
\end{tabular}

Standard deviations in parentheses. A respondent is considered as living in a mineral state if she lives in a state with more mineral resources than the median US state. Opposition to redistribution is the first principal component of two variables. The first is the answer, on a scale from 1 to 5, to the following question: "Some people think that the government in Washington should do everything possible to improve the standard of living of all poor Americans. Other people think it is not the government's responsibility, and that each person should take care of himself. Where would you place yourself on this scale?". This question is labeled support for individual responsibility in the table. The second is the answer, on scale from 1 to 7, to the following question: "Some people think that the government in Washington ought to reduce the income differences between the rich and the poor, perhaps by raising the taxes of wealthy families or by giving income assistance to the poor. Others think that the government should not concern itself with reducing this income difference between the rich and the poor. What score [...] comes closest to the way you feel?". This question is labeled sympathy for income inequality in the table. Reported p-values are associated to the following test: $\mathbb{E}(Y \mid$ Mineral states $) \neq \mathbb{E}(Y \mid$ Non mineral states $)$ where $Y$ is the variable specified at the start of each line. 
Table 2: Residence in a mineral state and opposition to redistribution.

Dependent variable: Opposition to redistribution (3)

Mineral state

\begin{tabular}{c}
\hline \\
$0.074^{* * *}$ \\
$(0.017)$ \\
$0.162^{* * *}$ \\
$(0.015)$ \\
$-0.145^{* * *}$ \\
$(0.029)$ \\
$0.018^{* * *}$ \\
$(0.003)$ \\
$0.153^{* * *}$ \\
$(0.017)$ \\
$0.098^{* * *}$ \\
$(0.021)$ \\
0.035 \\
$(0.024)$ \\
$0.045^{* * *}$ \\
$(0.003)$ \\
$0.059^{* * *}$ \\
$(0.018)$ \\
$0.466^{* * *}$ \\
$(0.025)$ \\
$0.061^{* * *}$ \\
$(0.005)$ \\
$0.208^{* * *}$ \\
$(0.006)$ \\
$0.115^{* * *}$ \\
$(0.016)$
\end{tabular}

Longitude

$(0.016)$

Population density

Per capita income

Gini coefficient

Region fixed effects

Origin and industry fixed effects

$0.063^{* * *}$
$(0.024)$
$0.159^{* * *}$
$(0.015)$
$-0.143^{* * *}$
$(0.029)$
$0.017^{* * *}$
$(0.003)$
$0.152^{* * *}$
$(0.017)$
$0.086^{* * *}$
$(0.022)$
$0.053^{* *}$
$(0.024)$
$0.046^{* * *}$
$(0.003)$
$0.058^{* * *}$
$(0.018)$
$0.466^{* * *}$
$(0.025)$
$0.062^{* * *}$
$(0.005)$
$0.206^{* * *}$
$(0.007)$
$0.117^{* * *}$
$(0.016)$
$0.262^{* *}$
$(0.127)$
0.006
$(0.008)$
-0.001
$(0.003)$
$-0.690^{*}$
$(0.364)$
Yes

$0.077^{* * *}$
$(0.017)$
$0.141^{* * *}$
$(0.016)$
$-0.129^{* * *}$
$(0.029)$
$0.016^{* * *}$
$(0.003)$
$0.150^{* * *}$
$(0.017)$
$0.107^{* * *}$
$(0.022)$
$0.053^{*}$
$(0.027)$
$0.051^{* * *}$
$(0.004)$
$0.059^{* * *}$
$(0.020)$
$0.357^{* * *}$
$(0.035)$
$0.059^{* * *}$
$(0.005)$
$0.208^{* * *}$
$(0.007)$
$0.103^{* * *}$
$(0.017)$

$0.061^{* *}$

$(0.024)$

$0.139 * * *$

(0.016)

$-0.128^{* * *}$

(0.030)

$0.016^{* * *}$

(0.003)

$0.149^{* * *}$

(0.017)

$0.097^{* * *}$

(0.023)

$0.067^{* *}$

(0.027)

$0.051^{* * *}$

(0.004)

$0.058 * * *$

(0.020)

$0.357^{* * *}$

$(0.035)$

$0.059 * * *$

(0.005)

$0.206^{* * *}$

(0.007)

$0.107^{* * *}$

(0.017)

$0.267^{*}$

(0.136)

0.008

(0.008)

$-0.001$

(0.003)

$-0.459$

(0.366)

Yes

Yes

\begin{tabular}{lllll}
\hline Observations & 20,193 & 20,193 & 19,176 & 19,176 \\
\hline \hline
\end{tabular}

*** $\mathrm{p}<0.01, * * \mathrm{p}<0.05$, $^{*} \mathrm{p}<0.1$. White heteroskedastic standard errors in parentheses, clustered by state $\times$ year. OLS regressions. All regressions include a constant term and year of interview fixed effects. Mineral state is equal to 1 if the respondent lives in a state with more mineral resources than the median US state, 0 if not. See the Online Appendix for the detailed definitions of other covariates. Opposition to redistribution, the dependent variable, is the first principal component of two variables. The first is the answer, on a scale from 1 to 5 , to the following question: "Some people think that the government in Washington should do everything possible to improve the standard of living of all poor Americans. Other people think it is not the government's responsibility, and that each person should take care of himself. Where would you place yourself on this scale?". The second is the answer, on scale from 1 to 7 , to the following question: "Some people think that the government in Washington ought to reduce the income differences between the rich and the poor, perhaps by raising the taxes of wealthy families or by giving income assistance to the poor. Others think that the government should not concern itself with reducing this income difference between the rich and the poor. What score [...] comes closest to the way you feel?". 
Table 3: Residence in a mineral state and opposition to redistribution: various measures of mines' presence.

Dependent variable: Opposition to redistribution

Number of mines (log of)

Mines per inhabitant (log of)

$0.015^{* * *}$

$0.012^{* *}$

$(0.003)$

$0.015^{* * *}$

$(0.006)$

$(0.003)$

$0.010^{*}$

Mines per square miles (log of)

$0.016^{* * *}$

(0.005)

(0.005)

0.006

Discounted number of mines (5\%)

$0.006^{* * *}$

$(0.007)$

(0.001)

$0.004^{*}$

$0.011^{* * *}$

(0.002)

Discounted number of mines (10\%)

(0.002)

$0.007^{* *}$

Yes

(0.004)

Individual covariates

State-level covariates

Origin and industry fixed effects

*** $\mathrm{p}<0.01,{ }^{*} \mathrm{p}<0.05,{ }^{*} \mathrm{p}<0.1$. White heteroskedastic standard errors in parentheses, clustered by state $\times$ year. OLS regressions. Each cell presents the estimate from a distinct regression. All regressions include a constant term and year of interview fixed effects. Regressions whose estimate is presented in column 1 include individual covariates used in Table 2 column 1. Regressions whose estimates are presented in column 2 include all covariates used in Table 2 column 4. Discounted number of mines is the discounted sum of mines discovered in a state. The yearly discount factor is either $5 \%$ or $10 \%$. Number of mines is the log of 1 plus the total number of mines in a state. Mines per inhabitant is the log of 1 plus the number of mines per inhabitant. Mines per square mile is the log of 1 plus the number of mines per square mile. Opposition to redistribution, the dependent variable, is the first principal component of two variables. The first is the answer, on a scale from 1 to 5 , to the following question: "Some people think that the government in Washington should do everything possible to improve the standard of living of all poor Americans. Other people think it is not the government's responsibility, and that each person should take care of himself. Where would you place yourself on this scale?". The second is the answer, on scale from 1 to 7 , to the following question: "Some people think that the government in Washington ought to reduce the income differences between the rich and the poor, perhaps by raising the taxes of wealthy families or by giving income assistance to the poor. Others think that the government should not concern itself with reducing this income difference between the rich and the poor. What score [...] comes closest to the way you feel?". 
Table 4: Residence in a mineral state, exposure to mineral discoveries and opposition to redistribution.

Dependent variable: Opposition to redistribution

$(1)$

\begin{tabular}{ccccc}
\hline & & & & \\
$0.049^{* *}$ & $0.059^{* *}$ & $0.042^{*}$ & $0.049^{*}$ & $0.071^{* *}$ \\
$(0.023)$ & $(0.027)$ & $(0.023)$ & $(0.027)$ & $(0.031)$ \\
$0.072^{* * *}$ & $0.064^{* *}$ & $0.081^{* * *}$ & $0.098^{* * *}$ & $0.094^{* * *}$ \\
$(0.025)$ & $(0.025)$ & $(0.025)$ & $(0.029)$ & $(0.030)$ \\
Yes & Yes & Yes & Yes & Yes \\
& Yes & & & Yes \\
& Yes & & & Yes \\
& & & Yes & Yes \\
& & Yes & & Yes
\end{tabular}

Mineral state

Mineral discoveries observed

Individual covariates

State-level covariates

Origin and industry fixed effects

Past family income and past per capita income

Birth cohort fixed effects

*** $\mathrm{p}<0.01, * * \mathrm{p}<0.05, * \mathrm{p}<0.1$. White heteroskedastic standard errors in parentheses, clustered by state $\times$ year. OLS regressions. All regressions include a constant term, year of interview fixed effects, and individual covariates used in Table 2 State-level covariates include population density, per capita income and Gini coefficient. The sample is restricted to individuals living in the same state at the time of interview and when they were young. Mineral state is equal to 1 if the respondent lives in a state with more mineral resources than the median US state, 0 if not. Mineral discoveries observed equals 1 if there has been mineral discoveries in the state during the respondent's life. Opposition to redistribution, the dependent variable, is the first principal component of two variables. The first is the answer, on a scale from 1 to 5 , to the following question: "Some people think that the government in Washington should do everything possible to improve the standard of living of all poor Americans. Other people think it is not the government's responsibility, and that each person should take care of himself. Where would you place yourself on this scale?". The second is the answer, on scale from 1 to 7 , to the following question: "Some people think that the government in Washington ought to reduce the income differences between the rich and the poor, perhaps by raising the taxes of wealthy families or by giving income assistance to the poor. Others think that the government should not concern itself with reducing this income difference between the rich and the poor. What score [...] comes closest to the way you feel?". 